\title{
MAFLD/NAFLD Biopsy-Free Scoring Systems for Hepatic Steatosis, NASH, and Fibrosis Diagnosis
}

\author{
Nancy de los Ángeles Segura-Azuara ${ }^{1 \dagger}$, Carlos Daniel Varela-Chinchilla ${ }^{1 \dagger}$ and \\ Plinio A. Trinidad-Calderón ${ }^{2 *}$
}

${ }^{1}$ Tecnológico de Monterrey, School of Medicine, and Health Sciences, Monterrey, Mexico, ${ }^{2}$ Tecnológico de Monterrey, School of Engineering, and Sciences, Monterrey, Mexico

Metabolic dysfunction-associated fatty liver disease (MAFLD), formerly known as nonalcoholic fatty liver disease, is the most prevalent liver disorder worldwide. Historically, its diagnosis required biopsy, even though the procedure has a variable degree of error. Therefore, new non-invasive strategies are needed. Consequently, this article presents a thorough review of biopsy-free scoring systems proposed for the diagnosis of MAFLD. Similarly, it compares the severity of the disease, ranging from hepatic steatosis (HS)

OPEN ACCESS

Edited by:

Ana Sandoval-Rodriguez,

University Center of Health Sciences,

University of Guadalajara, Mexico

Reviewed by:

Debjyoti Kundu,

Indiana University Bloomington,

United States

Ana Rosa Rincon-Sanchez,

University of Guadalajara, Mexico

${ }^{*}$ Correspondence:

Plinio A. Trinidad-Calderón

plinio.trinidad@tec.mx

${ }^{\dagger}$ These authors share first authorship

Specialty section:

This article was submitted to

Gastroenterology,

a section of the journal

Frontiers in Medicine

Received: 10 September 2021

Accepted: 10 December 2021

Published: 13 January 2022

Citation:

Segura-Azuara Ndlí,

Varela-Chinchilla $C D$ and

Trinidad-Calderón PA (2022)

MAFLD/NAFLD Biopsy-Free Scoring

Systems for Hepatic Steatosis, NASH,

and Fibrosis Diagnosis.

Front. Med. 8:774079.

doi: 10.3389/fmed.2021.774079 and nonalcoholic steatohepatitis (NASH) to fibrosis, by contrasting the corresponding serum markers, clinical associations, and performance metrics of these biopsy-free scoring systems. In this regard, defining MAFLD in conjunction with non-invasive tests can accurately identify patients with fatty liver at risk of fibrosis and its complications. Nonetheless, several biopsy-free scoring systems have been assessed only in certain cohorts; thus, further validation studies in different populations are required, with adjustment for variables, such as body mass index (BMI), clinical settings, concomitant diseases, and ethnic backgrounds. Hence, comprehensive studies on the effects of age, morbid obesity, and prevalence of MAFLD and advanced fibrosis in the target population are required. Nevertheless, the current clinical practice is urged to incorporate biopsy-free scoring systems that demonstrate adequate performance metrics for the accurate detection of patients with MAFLD and underlying conditions or those with contraindications of biopsy.

Keywords: MAFLD, NAFLD (non alcoholic fatty liver disease), scoring-algorithm, biopsy, steatosis, NASH, fibrosis, diagnosis

\section{INTRODUCTION}

Metabolic dysfunction-associated fatty liver disease (MAFLD), formerly known as nonalcoholic fatty liver disease (NAFLD), is the most prevalent liver disorder worldwide $(1,2)$. Besides being considered a major public health concern $(3,4)$, it is expected to become the leading cause of liver failure requiring transplantation by 2030 (5).

Specifically, NAFLD is defined as an increase in hepatic lipid content not associated with chronic hepatitis due to viral infections, autoimmune diseases, or the use of steatogenic medications (6-9). Moreover, NAFLD can progress from steatosis to nonalcoholic steatohepatitis (NASH), fibrosis, and eventually, cirrhosis and hepatocellular carcinoma (10). In its early phases, the disease has a silent presentation, thus hindering the diagnosis and placing patients at risk of worse clinical outcomes $(11,12)$. 
Nowadays, NAFLD is considered the hepatic component of metabolic syndrome (metabolic syndrome) (13), a disorder intricately related to type 2 diabetes mellitus (T2DM) (14, 15), insulin resistance, and cardiovascular diseases (16). For this reason, some authors have proposed a new, flexible term, MAFLD (17-19) (Figure 1).

Historically, MAFLD/NAFLD diagnosis required liver biopsy (20). Liver biopsy is a painful, invasive procedure that can increase mortality from 0.009 to $0.14 \%$, has a risk of intraperitoneal hemorrhage, and only assesses approximate 1 per 50,000 of the entire liver parenchyma (21). In response, the need for new non-invasive strategies has been evidenced (22-25), especially for patients with underlying conditions (26) or biopsy contraindications (27).

Recently, grouping several non-invasive serological biomarkers has become a trend for the prediction and diagnosis of liver fibrosis (28). Moreover, studies have shown that these systems may avoid up to $38-80 \%$ of liver biopsies $(29,30)$. Currently, no single marker has been used for the precise detection of MAFLD/NAFLD, as isolated biomarkers do not provide sufficiently accurate information for diagnosis (31-33). However, when coupled with clinical features and with each other, accurate diagnosis, staging, and prognosis for this disease become possible (34).

Therefore, this review presents the state-of-the-art biopsy-free scoring systems (BFSS) for the diagnosis of MAFLD/NAFLD. Moreover, it further contrasts, in a stratified arrangement (Figure 1) of hepatic steatosis (HS), $\mathrm{NASH}$, and fibrosis, the biomarkers, clinical associations, and discriminating performance metrics (Table 1) of such BFSS.

\section{HEPATIC STEATOSIS SCORING SYSTEMS}

Defined as a lipid concentration $>5 \%$ in the hepatic parenchyma (66) without portal or lobular inflammation (67), HS is the mildest form of MAFLD/NAFLD (68). Currently, $4 \%$ of patients with HS are expected to develop fibrosis in their lifetimes (69). Thus, the BFFS proposed to aid in the prompt diagnosis are discussed in this section.

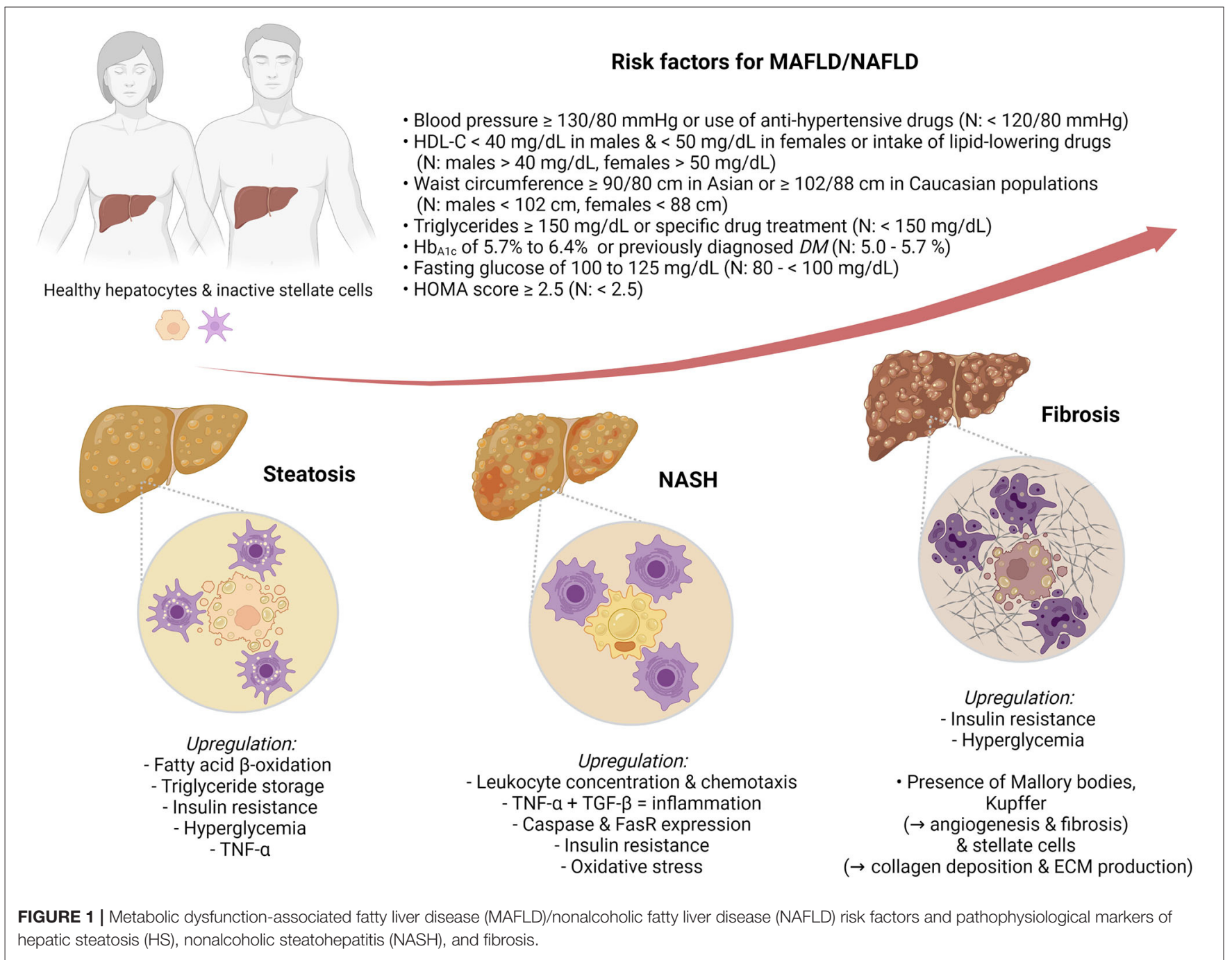


TABLE 1 | Performance metrics and calculation formulas of biopsy-free scoring systems for metabolic dysfunction-associated fatty liver disease (MAFLD)/nonalcoholic fatty liver disease (NAFLD) staging.

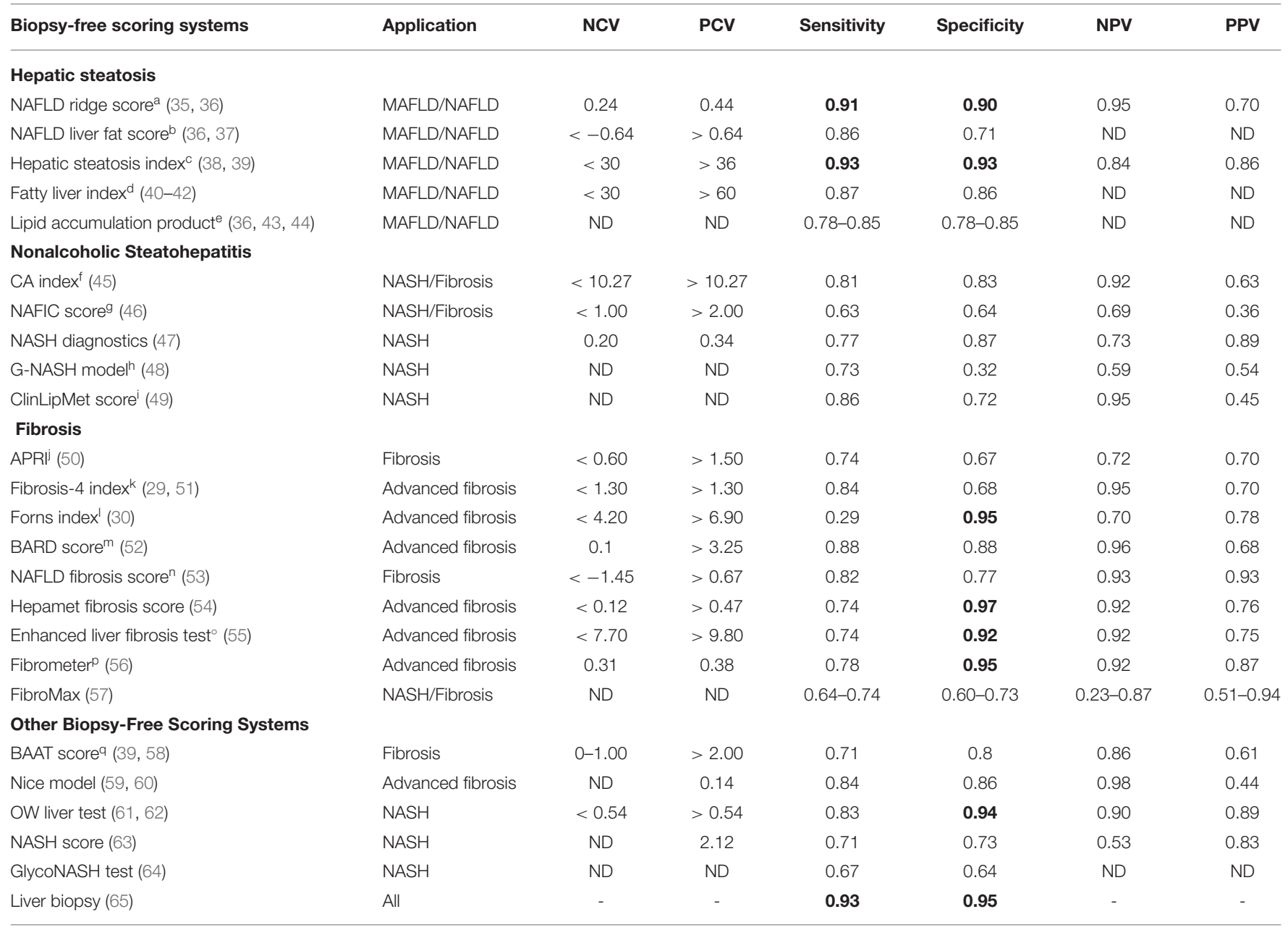

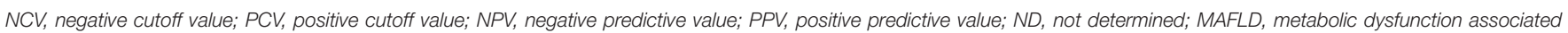
fatty liver disease; NAFLD, nonalcoholic fatty liver disease; NASH, nonalcoholic steatohepatitis. Bold values denote figures of sensitivity and specify above 0.90.

Calculation formulas:

${ }^{a} N R S:-0.614+0.007 \times A L T-0.214 \times H D L C+0.053 \times$ triglycerides $+0.144 \times H b A 1 C+0.032 \times W B C+0.132 \times$ hypertension.

${ }^{b} N L F S: 1.18 \times M S+T 2 D M(2$ if yes; 0 if no) $+0.15 \times$ fasting insulin $(m U / L)+0.04 \times A S T(U / L) 0.94 \times(A S T / A L T) 2.89$.

${ }^{c} \mathrm{HSI}: 8 \times($ ALT $/$ AST ratio $)+B M I(+2$, if female; +2 , if T2DM).

${ }^{d} F L I: e^{0.953} \times \log _{e}^{(T G)}+0.139 \times B M I+0.718 \times \log _{e}^{(G G T)}+0.053 \times W C-15.745 /\left[1+e^{0.953} \times \log _{e}{ }^{(T G)}+0.139 \times B M I+0.718 \times L^{(O O} e_{e}^{(G G T)}+0.053 \times W C-15.745\right] \times 100$. ${ }^{e} L A P:(W B C 65) \times$ triglycerides if male; (WBC 58) $\times$ triglycerides if female.

${ }^{f} \mathrm{CA}:(0.994 \times$ type IV collagen $7 \mathrm{~S}+0.0255 \times$ AST $)$.

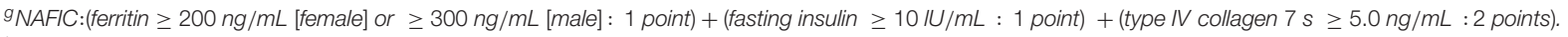

${ }^{h} \mathrm{G}-\mathrm{NASH}: 0.02 \times \mathrm{GP73}(\mathrm{ng} / \mathrm{ml})+0.123 \times A S T(U / L)+0.1576 \times$ zinc $(\mu \mathrm{mol} / \mathrm{L})+0.0227 \times$ total thyrosine $(\mathrm{nmol} / \mathrm{L})-0.4525 \times S D P V(f L)+2.0789 \times(B M I \geq 30 \mathrm{~kg} / \mathrm{m} 2, y e s=1, n o=0)$. ${ }^{i}$ ClinLipMet: $-0.305+0.562 \times$ PNPLA3 genotype $(C C-1 / G C-2 / G C-3) 0.0092 \times$ fasting insulin $(\mathrm{mU} / L)+0.0023 \times A S T(I U / L)+0.0019 \times($ fasting insulin $\times$ AST) .

${ }^{j}$ APRI: $\{$ AST (IU/1)/[upper normal value of $\left.41(I U / I)]\right\} /$ platelets $\left(\times 10^{9} / \mathrm{I}\right) \times 100$.

${ }^{k}$ FIB - 4: age $\times$ AST $(I U / I) /$ platelets $(\times 109 / I) \times \sqrt{ } A L T(I U / I)$.

IForns: $7.811-3.131 \times \ln$ (platelets) $+0.781 \times \ln (G G T)+3.467 \times \ln ($ age $)-$ cholesterol.

$m_{B A R D}:(B M I>28=1$ point $)+(A A R>0.8=2$ points $)+(D M=1$ point $)$.

${ }^{n}$ NFS: $1.675+[0.037 \times$ age $]+\left[0.094 \times B M I\left(\mathrm{~kg} / \mathrm{m}^{2}\right)\right]+[1.13 \times$ abnormal FGL or T2DM $($ yes $=1$, no $=0)]+[0.99 \times A A R]\left[0.013 \times\right.$ platelets $\left.\left(\times 10^{9} / \mathrm{l}\right)\right][0.66 \times$ albumin $(\mathrm{g} / \mathrm{d} /)]$. ${ }^{\circ} E L F: 2.494+0.846 \ln (H A)+0.735 \ln (P I I N P)+0.391 \ln (T I M P 1)$.

PFibrometer: 0.4184 glucose $(\mathrm{mmol} / L)+0.0701 \mathrm{AST}(\mathrm{IU} / \mathrm{L})+0.0008$ ferritin $(\mu \mathrm{g} / \mathrm{L})-0.0102$ platelet $(\mathrm{G} / \mathrm{L})-0.0260 \mathrm{ALT}(\mathrm{UI} / \mathrm{L})+0.0459 \mathrm{body}$ weight $(\mathrm{kg})+0.0842 \mathrm{age}+11.6226$. ${ }^{a} B A A T:(B M I \geq 28=1$ point $)+($ age $\geq 50$ years $=1$ point $)+(A L T \geq 2 N(1$ point $))+($ triglycerides $\geq 1.7 \mathrm{mmol} / L(1$ point $))$.

\section{NAFLD Ridge Score}

This BFSS considers alanine aminotransferase (ALT), hemoglobin $A_{1 C}$, high-density lipoprotein $C$, hypertension, leukocyte count, and triglycerides (35). The enzyme ALT level increases in serum as hepatocytes are damaged (36). Similarly, high levels of triglycerides, low levels of high-density lipoprotein $\mathrm{C}$, hypertension, and increased hemoglobin $\mathrm{A}_{1 \mathrm{C}}$ level correlate with HS $(70,71)$. Moreover, increased intrahepatic leukocyte concentration is associated with the progression to NAFLD risk factors and stage-specific markers of NASH $(72,73)$. 
Notably, this score has an area under the receiver-operating curve (AUROC) of 0.87 (74). Nevertheless, it is unreliable for distinguishing steatosis grades (36) and ends up classifying as indeterminate up to $30 \%$ of patients (35).

\section{NAFLD Liver Fat Score}

Developed in a Finnish population (37), this BFSS weighs aspartate aminotransferase (AST), AST/ALT ratio, fasting insulin, metabolic syndrome, and T2DM (75). Insulin levels correlate with HS grades, as insulin resistance is an important risk factor for the development of MAFLD/NAFLD (70). Moreover, AST levels increase as AST is released from injured hepatocytes, indicating liver dysfunction (36).

This BFSS can predict MAFLD/NAFLD and estimate the liver fat contents $>5.56 \%$, with an AUROC of $0.88(36,37)$. Moreover, it has shown a positive correlation with the incidence and mortality of cardiovascular disease, which are outcomes intricately related to metabolic syndrome and T2DM (76). Nonetheless, this score has a poor capacity for quantifying steatosis, as its AUROC for predicting $>33 \%$ of steatosis significantly decreases at 0.72 (77).

\section{HS Index}

This index assesses MAFLD/NAFLD (78) on the basis of body mass index (BMI), AST/ALT ratio, and the presence of T2DM (38). AST/ALT ratio is used to assess the HS grade more accurately than any of its components individually (79). Similarly, both enzymes positively and almost linearly correlated with increased incidence of MAFLD/NAFLD and premature mortality risk (80). In addition, studies have reported that this test has an AUROC of $0.75(78,81)$. Moreover, this BFSS has a high correlation with $\mathrm{HS}$ grades diagnosed using ultrasonography, but this score has not yet been validated for NASH (38).

\section{Fatty Liver Index}

Created as an algorithm to detect fatty liver (40), this index is based on BMI, gamma glutamyl transferase (GGT), triglycerides, and waist circumference (82). Waist circumference correlates with visceral adiposity, an important predictor of metabolic syndrome (83). Similarly, the accumulation of triglycerides in hepatocytes produces hepatocyte ballooning and inflammation, both changes associated with MAFLD/NAFLD (84). High levels of GGT, in particular, are associated with increased incidence rates of hypertension and insulin resistance (85).

The BFSS has an AUROC of 0.82 for MAFLD/NAFLD detection (86). However, it was validated only in certain populations, such as Koreans (82), Chinese (87), and Northern Italians (40).

\section{Lipid Accumulation Product}

The BFSS is used to evaluate waist circumference and triglyceride levels (43). Distinctively, it has been adjusted for age, sex, and ethnicity (88). This score is only validated in a cohort in Northern Italy (89). Although it was originally developed as a reference for cardiometabolic risk, it was later validated as an HS index $(36,44)$.
Furthermore, it has an AUROC, 0.77 for NAFLD diagnosis and was more accurate in patients with hypertriglyceridemia (AUROC, 0.73) compared with patients with T2DM (AUROC, $0.67)(86)$. However, even if the BFSS can detect MAFLD/NAFLD clinically, its main limitation is in distinguishing patients with mild disease from those with more severe MAFLD/NAFLD (90).

\section{NASH SCORING SYSTEMS}

Nonalcoholic steatohepatitis consists of fatty liver in conjunction with inflammation and hepatocellular injury, with or without fibrosis (91). More than $20 \%$ of patients with NASH are expected to develop cirrhosis in their lifetimes (69). Consequently, this section delves into the BFSS proposed for its detection $(92,93)$.

\section{CA Index}

This index owes its name to its two parameters, type IV collagen $7 \mathrm{~S}$ and AST. Specifically, type IV collagen $7 \mathrm{~S}$ is an indirect marker of fibrogenesis (94) and AST reiterates its role in liver dysfunction (36). Currently, the BFSS is used to predict NASH and fibrosis, with AUROC of 0.85 and 0.91 , respectively (95). Moreover, it identifies MAFLD/NAFLD without fibrosis and NASH-related fibrosis $(94,96)$. Unfortunately, the CA index was only validated in the Japanese population, similarly to the NAFIC score (97).

\section{NAFIC Score}

This score is based on ferritin, fasting insulin, and type IV collagen $7 \mathrm{~S}$ levels $(24,98)$. Comparatively, the BFSS is used for evaluating ferritin levels, which increases in patients with NASH (99). Similarly, fasting insulin is considered as a correlation marker for HS (70), and type IV collagen $7 \mathrm{~S}$ is used, as in the CA index (100).

The BFSS has an AUROC of 0.85 and 0.83 for NASH and fibrosis, respectively (46), both higher than the BARD [0.76 (101)] and NAFLD fibrosis score [0.77 (102)]. Nevertheless, such accuracy has been only validated in Japanese patients $(46,103)$.

\section{NASH Diagnostics}

This biomarker panel is used to diagnose obesity-related NASH based on adiponectin, cleaved cytokeratin 18 (CK-18) M30, and resistin levels (47). Adiponectin is inversely correlated with the risk of metabolic syndrome (104). Similarly, CK-18 M30 is proposed as a differentiator between NASH and MAFLD/NAFLD without inflammation $(24,105)$. Finally, resistin has been associated with obesity, insulin resistance, and T2DM $(106,107)$.

The BFFS has a reported AUROC value of 0.90 (47). However, it requires further validation in cohorts other than morbidly obese candidates for bariatric surgery (108). Similarly, a major limitation of its specificity is possibly due to all three of its parameters being increased in various liver diseases $(106,109)$, thus making them nonspecific markers of NASH $(110,111)$.

\section{G-NASH Model}

This novel BFSS is based on AST, BMI, CK-18 M30, Golgi protein 73 , platelets, thyroxine, and zinc (48). Specifically, CK$18 \mathrm{M} 30$ fragments increase in patients with MAFLD/NAFLD and T2DM (112), and correlate positively with high ALT, glucose, and 
hemoglobin $\mathrm{A}_{1 \mathrm{C}}$ levels, systolic blood pressure, and triglyceride levels (113). Similarly, Golgi protein 73, which is only expressed in fibrotic and diseased liver tissue, is considered a promising marker of liver inflammation (114).

When grouped (48), these biomarkers identified NASH in patients with MAFLD/NAFLD who had normal ALT levels and those requiring liver biopsy, with an AUROC of 0.85 (48). Nonetheless, the BFSS lacks external validation in other populations and studies to determine its validity for screening patients at risk of developing NASH (48).

\section{ClinLipMet Score}

Although it was only tested in Finnish and Belgian Caucasian and morbidly obese populations (49), the BFSS identified patients with NASH, with an AUROC of 0.866 (115). It considers AST and fasting insulin levels; PNPLA3 genotype rs738409, a polymorphism closely associated with increased hepatic fat content (116); and amino acid and phospholipid levels (49).

The levels of Glu, Gly, and Ile amino acids increase during progression to NASH (117). By contrast, phospholipids lysophosphatidylcholine 16:0 and phosphoethanolamine 40:6 are used to determine alterations in cell membrane metabolism in patients with advanced MAFLD/NAFLD and a higher liver fibrosis stage $(118,119)$. Specifically, these two molecules significantly differentiate NASH from HS but fail to do so in patients with HS and controls (49).

\section{HEPATIC FIBROSIS SCORING SYSTEMS}

Chronic injury to liver myofibroblasts is known to induce fibrosis (120). In this regard, the risk of advanced fibrosis in patients with MAFLD/NAFLD is noteworthy (7.5\%), along with other liver-related complications and eventually death $(52,121,122)$. Correspondingly, the BFSS proposed for the diagnosis of liver fibrosis is scrutinized herein.

\section{AST-to-Platelet Ratio Index}

The BFSS is based on AST and platelets, both of which increase in the hepatic sinusoids of patients with MAFLD/NAFLD (123, 124). In addition, it detects advanced fibrosis in patients with chronic hepatitis $\mathrm{C}$ virus infection (125) and is later validated for the detection of MAFLD/NAFLD (126).

The AST-to-platelet ratio index (APRI) is considered a good predictor of advanced fibrosis in patients with MAFLD/NAFLD, having an AUROC of 0.71 and 0.79 in non-bariatric and bariatric patients, respectively (127). Notwithstanding, some authors have argued against its widespread use, mainly because of its low accuracy in staging fibrosis $(128,129)$.

\section{Fibrosis-4 Index}

This index had been validated for the assessment and detection of liver fibrosis based on age, ALT level, AST level, and platelet count $(130,131)$. Platelet count correlates with hepatocyte ballooning, fibrosis, and liver steatosis $(123,124)$.

Overall, the BFSS has an AUROC ranging from 0.80 to 0.86 (128). Specifically for non-bariatric and bariatric patients, it has an AUROC of 0.83 and 0.81 , respectively, which are higher than those obtained for APRI (0.71 and 0.79, respectively) (127). Nonetheless, certain studies have argued that the inclusion of age might lead to a falsely worse score in the elderly population and thus increase the false-positive rate (132).

\section{Forns Index}

This index is based on platelet count, cholesterol level, GGT levels, and age $(133,134)$. The importance of this index relies on GGT, which has been associated with insulin resistance (85), and on cholesterol, which correlates negatively with the liver fibrosis stage, thus aiding in NASH diagnosis (30). In this regard, the BFSS is used as a predictor of advanced fibrosis in patients with chronic hepatitis $\mathrm{C}$ virus infections, with an AUROC of $0.79(30,105,134,135)$. Notwithstanding, information regarding its accuracy in MAFLD/NAFLD is limited (30).

\section{BARD Score}

The BARD score is based on BMI, AST/ALT ratio, and T2DM, all of which are markers of metabolic syndrome (61). Along with the NAFLD fibrosis and FIB-4 scores, the BFSS is validated for the detection of advanced fibrosis or cirrhosis, with an AUROC of $0.76(101,130)$. Even so, its low positive predictive value of 0.42 has limited its use in clinical practice (122). Nonetheless, its high reported negative predictive value of 0.96 makes the BARD score a reliable tool for ruling out advanced fibrosis (52).

\section{NAFLD Fibrosis Score}

The BFSS is currently used to predict advanced fibrosis (53), with an AUROC of 0.77 (102), and includes age, hyperglycemia, BMI, platelet count, albumin level, and AST/ALT ratio as parameters (136). Specifically, the albumin binding function and quantity are decreased in patients with long-standing MAFLD/NAFLD (137).

A high score $(>0.68)$ significantly correlated with a 4 -fold higher risk of death in patients with MAFLD/NAFLD (5). Nevertheless, this score has a limited value in predicting changes in fibrosis, even when it accurately predicts morbidity and mortality in all stages of fibrosis (138).

\section{Hepamet Fibrosis Score}

This novel BFSS is based on age; albumin, AST, and glucose levels; homeostatic metabolic assessment, which positively correlated with a higher stage of liver fibrosis and stiffness (139); insulin level; platelet count; sex; and T2DM (54, 140). It has a high accuracy for advanced fibrosis exclusion (30), with a reported AUROC value of 0.94 for advanced fibrosis prediction (30). Even so, this score had confounding results in patients with T2DM (141), a finding that created uncertainty because more than $70 \%$ of such patients concomitantly have MAFLD/NAFLD (142).

\section{Enhanced Liver Fibrosis Test}

This test is based on the levels of hyaluronic acid, type III procollagen peptide, and the tissue inhibitor of metalloproteinase 1 (143). Their concentrations and activities make this test useful for grading liver fibrosis (144, 145). In addition, studies have shown that the BFSS is an accurate tool for 
detecting advanced fibrosis in patients with MAFLD/NAFLD (146), mainly owing to its AUROC of 0.85 for stage F2 and 0.90 for stage F3 with NASH (147). Recently, a metaanalysis revealed that this fibrosis test has a high sensitivity for advanced fibrosis, but a limited specificity in low-prevalence areas (148).

\section{FibroMeter}

On the basis of markers, such as age, ALT level, AST level, body weight, ferritin level, glucose level, and platelet counts (149). FibroMeter identifies fibrotic areas and fibrosis stage (150), with higher reproducibility when compared with other diagnostic tools (149). Quantitatively, FibroMeter has AUROC values of $0.94,0.93$, and 0.9 for significant fibrosis, advanced fibrosis, and cirrhosis, respectively $(58,149)$. Furthermore, its results for fibrotic areas have an AUROC of 0.94, which is more accurate in comparison with that of the NAFLD fibrosis score (0.88) and APRI $(0.87)(7,7,149,151,152)$. Nonetheless, some authors argued that ethnicity-specific cutoff values would increase its validity (153).

\section{FibroMax}

FibroMax is a BFSS that combines five components into one algorithm (154). Among the components, ActiTest showed a significant accuracy in NASH diagnosis and MAFLD/NAFLD differentiation (155). It is considered as an accurate score for liver fibrosis $(154,156)$, with an AUROC of 0.68 for grade 2 and 3 steatosis, 0.59 for NASH, and 0.79 for fibrosis (157).

Furthermore, studies reported that FibroTest, another component of FibroMax, had higher accuracy in discriminating severe fibrosis stages and detecting cirrhosis than low to intermediate stages (158). FibroTest is not accurate for differentiating between the zonal distribution of fibrosis in MAFLD/NAFLD; thus, its effectiveness has been controversial (156).

Nonetheless, both components are affected by acute hemolysis, inflammation, and extrahepatic cholestasis (51). Similarly, in response to its low AUROC, they are considered unreliable alternatives for liver biopsy in MAFLD/NAFLD (157).

\section{DISCUSSION}

Numerous authors have proposed biopsy-free scoring systems as screening tools for fatty liver and risk-stratifying systems based on fibrosis $(51,144,159)$ for the MAFLD/NAFLD spectrum (95). Nonetheless, they still emphasize the importance of liver biopsy as the diagnostic standard but urge for a clear identification of biopsy indications (conflicting clinical or serological data), an issue that can be addressed with noninvasive diagnostic tools, such as BFSS (160-162). Some BFSSs addressed in this review (G-NASH, ClinLipMet, and enhanced liver fibrosis test) measure components that are not readily available, seldom ordered, or expensive, such as the PNPLA3 genotype, CK-18 M30 fragments, Golgi protein 73 , or the tissue inhibitor of metalloproteinase 1. Comparatively, other scores, such as the lipid accumulation product, fatty liver index, HS index, APRI, fibrosis-4 index, Forns index, and NAFLD fibrosis score rely on routinely ordered components, thus facilitating their use. Furthermore, as patients develop more metabolic abnormalities, they tend to yield higher scores $(163,164)$, making these BFSSs more reliable as the condition of the patient worsens. However, some scores have been validated only in limited populations, such as the CA index (97), fatty liver index $(40,82,87)$, and NAFIC score (46, 103), whereas others are inaccurate for MAFLD/NAFLD staging [FibroMax (157)] or when associated with other comorbidities [Hepamet fibrosis score (142)]. These limitations must be addressed through validation in other populations (97), with attention to variables, such as BMI, comorbidities, and ethnicity $(49,125,143,165-167)$. Comparatively, other BFSSs have been shown to have high sensitivity, such as the NAFLD ridge score $(35,36)$ or HS index $(38,39)$, and specificity, such as the Hepamet fibrosis score (54), Forns index (30), and enhanced liver fibrosis test (55), making them accurate tests for screening and confirmation of disease, respectively. Certain BFSSs underperformed in validation studies, such as the BAAT score (168), Nice model $(59,60)$, OW liver test $(61,62)$, NASH score (63), CHeK model (165), or GlycoNASH test (64), making them unsuitable alternatives for MAFLD/NAFLD diagnosis; thus, they were consequently excluded from the scrutiny of this review. Comprehensive studies on the effects of age, BMI, obesity, and the prevalence rates in different populations (101, $140,148,169)$ are required to determine the role of current and future BFSSs in MAFLD/NAFLD diagnosis. Other non-invasive alternatives have been proposed recently, such as cell-free DNA, which has been found in extracellular vesicles in the serum of patients with fatty liver, and have yielded promising results (170). Moreover, novel considerations, such as the addition of enhanced liver fibrosis test to clinical practice guidelines (171, 172) will eventually play a larger role in the diagnosis and follow-up of patients. As more information is gathered, novel considerations will be implemented, aiding in a more precise understanding and accurate detection of MAFLD/NAFLD in the global population (173).

\section{CONCLUDING REMARKS}

Clinicians are urged to include BFSS for the diagnosis of early stages of MAFLD/NAFLD, particularly in patients with a high risk of liver fibrosis, even if these are still outperformed by biopsy in terms of accuracy. Increasing the awareness of the available BFSSs for staging is paramount to improving patient safety. The ever-growing MAFLD/NAFLD pandemic urges clinicians to seek alternatives for screening, early diagnosis, and follow-up, especially for those with contraindications for liver biopsy.

\section{AUTHOR CONTRIBUTIONS}

NS-A, CV-C, and PT-C contributed to the conceptualization of this manuscript and its graphic elements, wrote and revised the original draft, and contributed to the discussion, abstract, and final version of the manuscript. CV-C further contributed to the revision, completion, and content improvement of the manuscript. PT-C further oversaw the general progress of the 
study, initial revision of the manuscript, structuring of the draft, and final revision of the manuscript, figures, and tables. All authors revised and agreed to the final version of the manuscript.

\section{FUNDING}

This work was supported by the Medical Publications and Conferences Support Fund 0020201D10 from Tecnológico de Monterrey.

\section{REFERENCES}

1. Tomic D, Kemp WW, Roberts SK. Nonalcoholic fatty liver disease: current concepts, epidemiology and management strategies. Eur J Gastroenterol Hepatol. (2018) 30:1103-15. doi: 10.1097/MEG.0000000000001235

2. Dietrich P, Hellerbrand C. Non-alcoholic fatty liver disease, obesity and the metabolic syndrome. Best Pract Res Clin Gastroenterol. (2014) 28:63753. doi: 10.1016/j.bpg.2014.07.008

3. Tiniakos DG, Vos MB, Brunt EM. Nonalcoholic fatty liver disease: pathology and pathogenesis. Annu Rev Pathol Mech Dis. (2010) 5:14571. doi: 10.1146/annurev-pathol-121808-102132

4. Hashimoto E, Taniai M, Tokushige K. Characteristics and diagnosis of NAFLD/NASH. J Gastroenterol Hepatol. (2013) 28:64-70. doi: 10.1111/jgh.12271

5. Rahadini A. Rahadina A. Does nafld fibrosis score predict mortality risk among mafld patients?: a systematic review and meta-analysis. Bali Med J. (2021) 10:595-9. doi: 10.15562/bmj.v10i2.2359

6. Cotter TG, Rinella M. Nonalcoholic fatty liver disease 2020: the state of the disease. Gastroenterology. (2020) 158:185164. doi: 10.1053 /j.gastro.2020.01.052

7. Grgurevic I, Podrug K, Mikolasevic I, Kukla M, Madir A, Tsochatzis EA. Natural history of nonalcoholic fatty liver disease: implications for clinical practice and an individualized approach. Can J Gastroenterol Hepatol. (2020) 2020:9181368. doi: 10.1155/2020/9181368

8. Younossi ZM, Koenig AB, Abdelatif D, Fazel Y, Henry L, Wymer M. Global epidemiology of nonalcoholic fatty liver disease-meta-analytic assessment of prevalence, incidence, and outcomes. Hepatology. (2016) 64:73-84. doi: $10.1002 /$ hep. 28431

9. Bellentani S. The epidemiology of non-alcoholic fatty liver disease. Liver Int. (2017) 37:81-4. doi: 10.1111/liv.13299

10. Fernando DH, Forbes JM, Angus PW, Herath CB. Development and progression of non-alcoholic fatty liver disease: The role of advanced glycation end products. Int $J$ Mol Sci. (2019) 20:5037. doi: 10.3390/ijms20205037

11. Newton JL. Systemic symptoms in non-alcoholic fatty liver disease. Dig Dis. (2010) 28:214-9. doi: 10.1159/000282089

12. Trovato FM, Castrogiovanni P, Malatino L, Musumeci G. Nonalcoholic fatty liver disease (NAFLD) prevention: role of Mediterranean diet and physical activity. HepatoBiliary Surg Nutr. (2019) 8:167-9. doi: $10.21037 / \mathrm{hbsn} .2018 .12 .05$

13. Eslam M, Newsome PN, Sarin SK, Anstee QM, Targher G, Romero-Gomez $\mathrm{M}$, et al. A new definition for metabolic dysfunction-associated fatty liver disease: an international expert consensus statement. J Hepatol. (2020) 73:202-9. doi: 10.1016/j.jhep.2020.03.039

14. Scorletti E, Byrne CD. Extrahepatic diseases and NAFLD: the triangular relationship between NAFLD, Type 2-diabetes and dysbiosis. Dig Dis. (2016) 34:11-8. doi: 10.1159/000447276

15. Lattuada G, Ragogna F, Perseghin G. Why does NAFLD predict type 2 diabetes? Curr Diab Rep. (2011) 11:167-72. doi: 10.1007/s11892-011-0190-2

16. Al Rifai M, Silverman MG, Nasir K, Budoff MJ, Blankstein R, Szklo M, et al. The association of nonalcoholic fatty liver disease, obesity, and metabolic syndrome, with systemic inflammation and subclinical atherosclerosis: the multi-ethnic study of atherosclerosis (MESA). Atherosclerosis. (2015) 239:629-33. doi: 10.1016/j.atherosclerosis.2015.02.011

\section{ACKNOWLEDGMENTS}

We recognize the role of BioRender.com in the creation of the figure in this manuscript and its sponsorship by Laura Margarita López-Castillo. PT-C thanks CONACyT for grant 627107 for his doctoral studies. Likewise, he thanks Tecnológico de Monterrey for his full-tuition scholarship and its support as part of the teaching assistant program.

17. Eslam M, Sanyal AJ, George J, Sanyal A, Neuschwander-Tetri B, Tiribelli C, et al. MAFLD: a consensus-driven proposed nomenclature for metabolic associated fatty liver disease. Gastroenterology. (2020) 158:19992014.e1. doi: 10.1053/j.gastro.2019.11.312

18. Fouad Y, Waked I, Bollipo S, Gomaa A, Ajlouni Y, Attia D. What's in a name? Renaming 'NAFLD' to 'MAFLD'. Liver Int. (2020) 40:125461. doi: $10.1111 /$ liv. 14478

19. Tilg H, Effenberger M. From NAFLD to MAFLD: when pathophysiology succeeds. Nat Rev Gastroenterol Hepatol. (2020) 17:387-8. doi: 10.1038/s41575-020-0316-6

20. Berger D, Desai V, Janardhan S. Con: liver biopsy remains the gold standard to evaluate fibrosis in patients with nonalcoholic fatty liver disease. Clin Liver Dis. (2019) 13:114-6. doi: 10.1002/cld.740

21. Zhang JZ, Cai JJ Yu Y, She ZG Li H. Nonalcoholic fatty liver disease: an update on the diagnosis. Gene Expr J Liver Res. (2019) 19:18798. doi: 10.3727/105221619X15553433838609

22. Arun J, Jhala N, Lazenby AJ, Clements R, Abrams GA. Influence of liver biopsy heterogeneity and diagnosis of nonalcoholic steatohepatitis in subjects undergoing gastric bypass. Obes Surg. (2007) 17:155-61. doi: 10.1007/s11695-007-9041-2

23. Iqbal U, Perumpail BJ, Akhtar D, Kim D. The epidemiology, risk profiling and diagnostic challenges of nonalcoholic fatty liver disease. Medicines. (2019) 1-19. doi: 10.3390/medicines6010041

24. Eguchi Y, Wong G, Akhtar O, Sumida Y. Non-invasive diagnosis of nonalcoholic steatohepatitis and advanced fibrosis in Japan: a targeted literature review. Hepatol Res. (2020) 50:645-55. doi: 10.1111/hepr.13502

25. Papatheodoridi M, Cholongitas E. Diagnosis of non-alcoholic fatty liver disease (NAFLD): current concepts. Curr Pharm Des. (2019) 24:457486. doi: $10.2174 / 1381612825666190117102111$

26. Leoni S, Tovoli F, Napoli L, Serio I, Ferri S, Bolondi L. Current guidelines for the management of non-alcoholic fatty liver disease: a systematic review with comparative analysis. World J Gastroenterol. (2018) 24:336173. doi: $10.3748 /$ wjg.v24.i30.3361

27. Khalifa A, Rockey DC. The utility of liver biopsy in 2020. Curr Opin Gastroenterol. (2020) 36:184-91. doi: 10.1097/MOG.0000000000000621

28. Zhang F, Liu T, Gao P, Fei S. Predictive value of a noninvasive serological hepatic fibrosis scoring system in cirrhosis combined with oesophageal varices. Can J Gastroenterol Hepatol. (2018) 2018. doi: 10.1155/2018/7671508

29. McPherson S, Stewart SF, Henderson E, Burt AD, Day CP. Simple noninvasive fibrosis scoring systems can reliably exclude advanced fibrosis in patients with non-alcoholic fatty liver disease. Gut. (2010) 59:12659. doi: 10.1136/gut.2010.216077

30. Ballestri S, Mantovani A, Baldelli E, Lugari S, Maurantonio M, Nascimbeni F, et al. Liver fibrosis biomarkers accurately exclude advanced fibrosis and are associated with higher cardiovascular risk scores in patients with NAFLD or viral chronic liver disease. Diagnostics. (2021) 11:98. doi: 10.3390/diagnostics11010098

31. Mansour AMF, Bayoumy EM, ElGhandour AM, El-Talkawy MD, Badr SM, Ahmed AEM. Assessment of hepatic fibrosis and steatosis by vibrationcontrolled transient elastography and controlled attenuation parameter versus non-invasive assessment scores in patients with non-alcoholic fatty liver disease. Egypt Liver J. (2020) 10:33. doi: 10.1186/s43066-020-00044-w

32. Mózes FE, Lee JA, Selvaraj EA, Jayaswal ANA, Trauner M, Boursier J, et al. Diagnostic accuracy of non-invasive tests for advanced fibrosis in 
patients with NAFLD: an individual patient data meta-analysis. Gut. (2021) 1-14. doi: 10.1136/gutjnl-2021-324243

33. Caussy C, Reeder SB, Sirlin CB, Loomba R. Non-invasive, quantitative assessment of liver fat by MRI-PDFF as an endpoint in NASH trials. Hepatology. (2019) 68:763-72. doi: 10.1002/hep.29797

34. Younossi Z, Anstee QM, Marietti M, Hardy T, Henry L, Eslam M, et al. Global burden of NAFLD and NASH: trends, predictions, risk factors and prevention. Nat Rev Gastroenterol Hepatol. (2018) 15:1120. doi: 10.1038/nrgastro.2017.109

35. Yip TCF, Ma AJ, Wong VWS, Tse YK, Chan HLY, Yuen PC, et al. Laboratory parameter-based machine learning model for excluding non-alcoholic fatty liver disease (NAFLD) in the general population. Aliment Pharmacol Ther. (2017) 46:447-56. doi: 10.1111/apt.14172

36. Drescher HK, Weiskirchen S, Weiskirchen R. Current Status in Testing for Nonalcoholic Fatty Liver Disease (NAFLD) and Nonalcoholic Steatohepatitis (NASH). Cells. (2019) 8. doi: 10.3390/cells8080845

37. Kotronen A, Peltonen M, Hakkarainen A, Sevastianova K, Bergholm R, Johansson LM, et al. Prediction of non-alcoholic fatty liver disease and liver fat using metabolic and genetic factors. Gastroenterology. (2009) 137:86572. doi: 10.1053/j.gastro.2009.06.005

38. Lee JH, Kim D, Kim HJ, Lee CH, Yang JI, Kim W, et al. Hepatic steatosis index: a simple screening tool reflecting nonalcoholic fatty liver disease. Dig Liver Dis. (2010) 42:503-8. doi: 10.1016/j.dld.2009.08.002

39. Jeong S, Kim K, Chang J, Choi S, Kim SM, Son JS, et al. Development of a simple nonalcoholic fatty liver disease scoring system indicative of metabolic risks and insulin resistance. Ann Transl Med. (2020) 8:14141414. doi: 10.21037/atm-20-2951

40. Bedogni G, Bellentani S, Miglioli L, Masutti F, Passalacqua M, Castiglione A, et al. The fatty liver index: a simple and accurate predictor of hepatic steatosis in the general population. BMC Gastroenterol. (2006) 6:17. doi: 10.1186/1471-230X-6-33

41. Calori G, Lattuada G, Ragogna F, Garancini MP, Crosignani P, Villa M, et al. Fatty liver index and mortality: The cremona study in the 15 th year of follow-up. Hepatology. (2011) 54:145-52. doi: 10.1002/hep.24356

42. Gastaldelli A, Kozakova M, Höjlund K, Flyvbjerg A, Favuzzi A, Mitrakou A, et al. Fatty liver is associated with insulin resistance, risk of coronary heart disease, and early atherosclerosis in a large European population. HepatoSlogy. (2009) 49:1537-44. doi: 10.1002/hep.22845

43. Taverna MJ, Martínez-Larrad MT, Frechtel GD, Serrano-Ríos M. Lipid accumulation product: a powerful marker of metabolic syndrome in healthy population. Eur J Endocrinol. (2011) 164:559-67. doi: 10.1530/EJE-10-1039

44. Bedogni G, Kahn HS, Bellentani S, Tiribelli C. A simple index of lipid overaccumulation is a good marker of liver steatosis. BMC Gastroenterol. (2010) 10. doi: 10.1186/1471-230X-10-98

45. Shima T, Sakai K, Oya H, Katayama T, Mitsumoto Y, Mizuno M, et al. Diagnostic accuracy of combined biomarker measurements and vibration-controlled transient elastography (VCTE) for predicting fibrosis stage of non-alcoholic fatty liver disease. J Gastroenterol. (2020) 55:10012. doi: 10.1007/s00535-019-01626-1

46. Sumida Y, Yoneda M, Hyogo H, Yamaguchi K, Ono M, Fujii H, et al. A simple clinical scoring system using ferritin, fasting insulin, and type IV collagen $7 \mathrm{~S}$ for predicting steatohepatitis in nonalcoholic fatty liver disease. $J$ Gastroenterol. (2011) 46:257-68. doi: 10.1007/s00535-010-0305-6

47. Younossi ZM, Jarrar M, Nugent C, Randhawa M, Afendy M, Stepanova $\mathrm{M}$, et al. A novel diagnostic biomarker panel for obesityrelated nonalcoholic steatohepatitis (NASH). Obes Surg. (2008) 18:1430-7. doi: 10.1007/s11695-008-9506-y

48. Zheng KI, Liu W-YY, Pan X-YY, Ma H-LL, Zhu P-WW, Wu X-XX, et al. Combined and sequential non-invasive approach to diagnosing nonalcoholic steatohepatitis in patients with non-alcoholic fatty liver disease and persistently normal alanine aminotransferase levels. BMJ Open Diabetes Res Care. (2020) 8:1-11. doi: 10.1136/bmjdrc-2020-001174

49. Zhou Y, Orešič M, Leivonen M, Gopalacharyulu P, Hyysalo J, Arola J, et al. Noninvasive detection of nonalcoholic steatohepatitis using clinical markers and circulating levels of lipids and metabolites. Clin Gastroenterol Hepatol. (2016) 14:1463-1472.e6. doi: 10.1016/j.cgh.2016.05.046

50. Loaeza-del-Castillo A, Paz-Pineda F, Oviedo-Cárdenas E, Sánchez-Ávila F, Vargas-Vorácková F. AST to platelet ratio index (APRI) for the noninvasive evaluation of liver fibrosis. Ann Hepatol. (2008) 7:350357. doi: 10.1016/S1665-2681(19)31836-8

51. Sun W, Cui H, Li N, Wei Y, Lai S, Yang Y, et al. Comparison of FIB-4 index, NAFLD fibrosis score and BARD score for prediction of advanced fibrosis in adult patients with non-alcoholic fatty liver disease: a meta-analysis study. Hepatol Res. (2016) 46:862-70. doi: 10.1111/hepr.12647

52. Cichoz-Lach H, Celiński K, Prozorow-Król B, Swatek J, Słomka M, Lach T. The BARD score and the NAFLD fibrosis score in the assessment of advanced liver fibrosis in nonalcoholic fatty liver disease. Med Sci Monit. (2012) 18:735-40. doi: 10.12659/MSM.883601

53. Angulo P, Hui JM, Marchesini G, Bugianesi E, George J, Farrell GC, et al. The NAFLD fibrosis score: a noninvasive system that identifies liver fibrosis in patients with NAFLD. Hepatology. (2007) 45:846-54. doi: 10.1002/hep. 21496

54. Ampuero J, Pais R, Aller R, Gallego-Durán R, Crespo J, García-Monzón $\mathrm{C}$, et al. Development and validation of hepamet fibrosis scoring systema simple, noninvasive test to identify patients with nonalcoholic fatty liver disease with advanced fibrosis. Clin Gastroenterol Hepatol. (2020) 18:216225.e5. doi: 10.1016/j.cgh.2019.05.051

55. Fagan KJ, Pretorius CJ, Horsfall LU, Irvine KM, Wilgen U, Choi K, et al. ELF score $\geq 98$ indicates advanced hepatic fibrosis and is influenced by age, steatosis and histological activity. Liver Int. (2015) 35:167381. doi: 10.1111/liv. 12760

56. Calès P, Lainé F, Boursier J, Deugnier Y, Moal V, Oberti F, et al. Comparison of blood tests for liver fibrosis specific or not to NAFLD. J Hepatol. (2009) 50:165-73. doi: 10.1016/j.jhep.2008.07.035

57. Bril F, McPhaul MJ, Caulfield MP, Castille JM, Poynard T, Soldevila-Pico C, et al. Performance of the SteatoTest, ActiTest, NashTest and FibroTest in a multiethnic cohort of patients with type 2 diabetes mellitus. J Investig Med. (2019) 67:303-11. doi: 10.1136/jim-2018-000864

58. Kaswala DH, Lai M, Afdhal NH. Fibrosis assessment in nonalcoholic fatty liver disease (NAFLD) in 2016. Dig Dis Sci. (2016) 61:135664. doi: 10.1007/s10620-016-4079-4

59. Alkhouri N, McCullough AJ. Noninvasive diagnosis of NASH and liver fibrosis within the spectrum of NAFLD. Gastroenterol Hepatol. (2012) 8:661-8.

60. Anty R, Iannelli A, Patouraux S, Bonnafous S, Lavallard VJ, Senni-Buratti $\mathrm{M}$, et al. A new composite model including metabolic syndrome, alanine aminotransferase and cytokeratin-18 for the diagnosis of non-alcoholic steatohepatitis in morbidly obese patients. Aliment Pharmacol Ther. (2010) 32:1315-22. doi: 10.1111/j.1365-2036.2010.04480.x

61. Iruarrizaga-Lejarreta M, Bril F, Noureddin M, Ortiz P, Lu S, Mato $\mathrm{J}$, et al. Emerging circulating biomarkers for the diagnosis and assessment of treatment responses in patients with hepatic fat accumulation, nash and liver fibrosis. Transl res methods diabetes, obesity, nonalcoholic fat liver dis a focus early phase. Clin Drug Dev. (2019) 423-448. doi: 10.1007/978-3-030-11748-1_16

62. Barr J, Caballería J, Martínez-Arranz I, Domínguez-Díez A, Alonso C, Muntané J, et al. Obesity dependent metabolic signatures associated with nonalcoholic fatty liver disease progression. J Proteome Res. (2012) 11:252132. doi: $10.1021 / \mathrm{pr} 201223 \mathrm{p}$

63. Hyysalo J, Männistö VT, Zhou Y, Arola J, Kärjä V, Leivonen M, et al. A population-based study on the prevalence of NASH using scores validated against liver histology. J Hepatol. (2014) 60:83946. doi: 10.1016/j.jhep.2013.12.009

64. Verhaegh P, Bavalia R, Winkens B, Masclee A, Jonkers D, Koek G. Noninvasive tests do not accurately differentiate nonalcoholic steatohepatitis from simple steatosis: a systematic review and meta-analysis. Clin Gastroenterol Hepatol. (2018) 16:837-61. doi: 10.1016/j.cgh.2017.08.024

65. Vilar-Gomez E, Lou Z, Kong N, Vuppalanchi R, Imperiale TF, Chalasani N. Cost Effectiveness of Different Strategies for Detecting Cirrhosis in Patients With Nonalcoholic Fatty Liver Disease Based on United States Health Care System. Clin Gastroenterol Hepatol. (2020) 18:2305-2314.e12. doi: 10.1016/j.cgh.2020.04.017

66. Nascimbeni F, Lugari S, Cassinerio E, Motta I, Cavicchioli A, Dalla Salda A, et al. Liver steatosis is highly prevalent and is associated with metabolic risk factors and liver fibrosis in adult patients with type 1 Gaucher disease. Liver Int. (2020) 40:3061-70. doi: 10.1111/liv.14640 
67. Mazzolini G, Sowa JP, Atorrasagasti C, Kücükoglu Ö, Syn WK, Canbay A. Significance of Simple Steatosis: an update on the clinical and molecular evidence. Cells. (2020) 9:1-19. doi: 10.3390/cells9112458

68. Moylan CA, Pang H, Dellinger A, Suzuki A, Garrett ME, Guy CD, et al. Hepatic gene expression profiles differentiate presymptomatic patients with mild versus severe nonalcoholic fatty liver disease. Hepatology. (2014) 59:471-82. doi: 10.1002/hep.26661

69. Sheka A, Adeyi O, Thompson J, Hameed B, Crawford P, Ikramuddin S. Nonalcoholic steatohepatitis a review. JAMA-J Am Med Assoc. (2020) 323:1175-83. doi: 10.1001/jama.2020.2298

70. Hsiao PJ, Kuo KK, Shin SJ, Yang YH, Lin WY, Yang JF, et al. Significant correlations between severe fatty liver and risk factors for metabolic syndrome. J Gastroenterol Hepatol. (2007) 22:2118-23. doi: 10.1111/j.1440-1746.2006.04698.x

71. Vanni E, Bugianesi E, Kotronen A, De Minicis S, Yki-Järvinen H, SvegliatiBaroni G. From the metabolic syndrome to NAFLD or vice versa? Dig Liver Dis. (2010) 42:320-30. doi: 10.1016/j.dld.2010.01.016

72. Roh YS, Seki E. Chemokines and chemokine receptors in the development of NAFLD. Adv Exp Med Biol. (2018) 1061:4553. doi: 10.1007/978-981-10-8684-7_4

73. Yoo HJ, Hwang SY, Choi JH, Lee HJ, Chung HS, Seo JA, et al. Association of leukocyte cell-derived chemotaxin 2 (LECT2) with NAFLD, metabolic syndrome, and atherosclerosis. PLoS ONE. (2017) 12:111. doi: 10.1371 /journal.pone. 0174717

74. Wong VWS, Adams LA, de Lédinghen V, Wong GLH, Sookoian S. Noninvasive biomarkers in NAFLD and NASH-current progress and future promise. Nat Rev Gastroenterol Hepatol. (2018) 15:46178. doi: 10.1038/s41575-018-0014-9

75. Unalp-Arida A, Ruhl CE. Liver fat scores predict liver disease mortality in the United States population. Aliment Pharmacol Ther. (2018) 48:100316. doi: $10.1111 /$ apt.14967

76. Lee CO Li HL, Tsoi MF, Cheung CL, Cheung BMY. Association between the liver fat score (LFS) and cardiovascular diseases in the national health and nutrition examination survey 1999-2016. Ann Med. (2021) 53:106573. doi: 10.1080/07853890.2021.1943514

77. Fedchuk L, Nascimbeni F, Pais R, Charlotte F, Housset C, Ratziu V. Performance and limitations of steatosis biomarkers in patients with nonalcoholic fatty liver disease. Aliment Pharmacol Ther. (2014) 40:120922. doi: $10.1111 /$ apt.12963

78. Sviklāne L, Olmane E, Dzērve Z, Kupčs K, Pirāgs V, Sokolovska J. Fatty liver index and hepatic steatosis index for prediction of non-alcoholic fatty liver disease in type 1 diabetes. J Gastroenterol Hepatol. (2018) 33:2706. doi: $10.1111 /$ jgh.13814

79. Zou Y, Zhong L, Hu C, Sheng G. Association between the alanine aminotransferase/aspartate aminotransferase ratio and new-onset nonalcoholic fatty liver disease in a nonobese Chinese population: a population-based longitudinal study. Lipids Health Dis. (2020) 19:110. doi: 10.1186/s12944-020-01419-z

80. Targher G, Byrne CD. Obesity: Metabolically healthy obesity and NAFLD. Nat Rev Gastroenterol Hepatol. (2016) 13:4424. doi: 10.1038/nrgastro.2016.104

81. Chen L Da, Huang JF, Chen QS, Lin GF, Zeng HX, Lin XF, et al. Validation of fatty liver index and hepatic steatosis index for screening of nonalcoholic fatty liver disease in adults with obstructive sleep apnea hypopnea syndrome. Chin Med J. (2019) 132:2670-6. doi: 10.1097/CM9.00000000000 00503

82. Khang AR, Lee HW Yi D, Kang YH, Son SM. The fatty liver index, a simple and useful predictor of metabolic syndrome: analysis of the Korea national health and nutrition examination survey 2010-2011. Diabetes, Metab Syndr Obes Targets Ther. (2019) 12:181-90. doi: 10.2147/DMSO.S1 89544

83. Lee J, Cho YK, Kang YM, Kim HS, Jung CH, Kim HK, et al. The impact of NAFLD and waist circumference changes on diabetes development in prediabetes subjects. Sci Rep. (2019) 9:1-8. doi: 10.1038/s41598-019$53947-\mathrm{Z}$

84. Kawano Y, Cohen DE. Mechanisms of hepatic triglyceride accumulation in non-alcoholic fatty liver disease. J Gastroenterol. (2013) 48:43441. doi: 10.1007/s00535-013-0758-5
85. Bonnet F, Gastaldelli A, Pihan-Le Bars F, Natali A, Roussel R, Petrie J, et al. Gamma-glutamyltransferase, fatty liver index and hepatic insulin resistance are associated with incident hypertension in two longitudinal studies. $J$ Hypertens. (2017) 35:493-500. doi: 10.1097/HJH.0000000000001204

86. Lind L, Johansson L, Ahlström H, Eriksson JW, Larsson A, Risérus $\mathrm{U}$, et al. Comparison of four non-alcoholic fatty liver disease detection scores in a Caucasian population. World J Hepatol. (2020) 12:14959. doi: 10.4254 /wjh.v12.i4.149

87. Huang X, Xu M, Chen Y, Peng K, Huang Y, Wang P, et al. Validation of the fatty liver index for nonalcoholic fatty liver disease in middle-aged and elderly Chinese. Medicine. (2015) 94. doi: 10.1097/MD.0000000000001682

88. Kahn HS. The "lipid accumulation product" performs better than the body mass index for recognizing cardiovascular risk: a population-based comparison. BMC Cardiovasc Disord. (2005) 5:1-10. doi: 10.1186/1471-2261-5-26

89. Dai H, Wang W, Chen R, Chen Z, Lu Y, Yuan H. Lipid accumulation product is a powerful tool to predict non-alcoholic fatty liver disease in Chinese adults. Nutr Metab. (2017) 14:1-9. doi: 10.1186/s12986-017-0206-2

90. Özcabi B, Demirhan S, Akyol M, Akay HÖ, Güven A. Lipid accumulation product is a predictor of nonalcoholic fatty liver disease in childhood obesity. Korean J Pediatr. (2019) 62:450-5. doi: 10.3345/kjp.2019.00248

91. Harrison SA, Rinella ME, Abdelmalek MF, Trotter JF, Paredes AH, Arnold HL, et al. NGM282 for treatment of non-alcoholic steatohepatitis: a multicentre, randomised, double-blind, placebo-controlled, phase 2 trial. Lancet. (2018) 391:1174-85. doi: 10.1016/S0140-6736(18)30474-4

92. Diehl AM, Day C. Cause, pathogenesis, and treatment of nonalcoholic steatohepatitis. N Engl J $\quad$ Med. (2017) 377:206372. doi: 10.1056/NEJMra1503519

93. Araújo AR, Rosso N, Bedogni G, Tiribelli C, Bellentani S. Global epidemiology of non-alcoholic fatty liver disease/non-alcoholic steatohepatitis: what we need in the future. Liver Int. (2018) 38:47-51. doi: 10.1111/liv.13643

94. Ishiba H, Sumida Y, Seko Y, Tanaka S, Yoneda M, Hyogo H, et al. Type IV collagen $7 \mathrm{~S}$ is the most accurate test for identifying advanced fibrosis in NAFLD with type 2 diabetes. Hepatol Commun. (2021) 5:55972. doi: 10.1002/hep4.1637

95. Okanoue T, Ebise H, Kai T, Mizuno M, Shima T, Ichihara J, et al. Simple scoring system using type IV collagen $7 \mathrm{~S}$ and aspartate aminotransferase for diagnosing nonalcoholic steatohepatitis and related fibrosis. J Gastroenterol. (2018) 53:129-39. doi: 10.1007/s00535-017-1355-9

96. Yoneda M, Imajo K, Takahashi H, Ogawa Y, Eguchi Y, Sumida Y, et al. Clinical strategy of diagnosing and following patients with nonalcoholic fatty liver disease based on invasive and noninvasive methods. J Gastroenterol. (2018) 53:181-96. doi: 10.1007/s00535-017-1414-2

97. Sumida Y, Shima T, Mitsumoto Y, Katayama T, Umemura A, Yamaguchi K, et al. Epidemiology: pathogenesis, and diagnostic strategy of diabetic liver disease in Japan. Int J Mol Sci. (2020) 21:1-18. doi: 10.3390/ijms21124337

98. Nakamura A. A caution in the use of the NAFIC scoring system as a diagnostic screening tool for nonalcoholic steatohepatitis. J Gastrointest Dig Syst. (2014) 4:221. doi: 10.4172/2161-069X.1000221

99. Shah RA, Kowdley K V. Serum ferritin as a biomarker for NAFLD: ready for prime time? Hepatol Int. (2019) 13:110-2. doi: 10.1007/s12072-019-09934-7

100. Tada $T$, Kumada $T$, Toyoda H, Saibara $T$, Ono $M$, Kage $M$. New scoring system combining the FIB-4 index and cytokeratin18 fragments for predicting steatohepatitis and liver fibrosis in patients with nonalcoholic fatty liver disease. Biomarkers. (2018) 23:328-34. doi: 10.1080/1354750X.2018.1425915

101. Meneses D, Olveira A, Corripio R, del Carmen Méndez M, Romero M, Calvo-Viñuelas I, et al. performance of noninvasive liver fibrosis scores in the morbid obese patient, same scores but different thresholds. Obes Surg. (2020) 30:2538-46. doi: 10.1007/s11695-020-04509-0

102. Kruger FC, Daniels CR, Kidd M, Swart G, Brundyn K, van Rensburg C, et al. A simple bedside marker for advanced fibrosis that can avoid liver biopsy in patients with NAFLD/NASH. South African Med J. (2011) 101:477-80.

103. Sumida $Y$, Nakajima A, Hyogo $H$, Tanaka S, Ono M, Fuji $H$, et al. Non-invasive scoring systems for predicting NASH in Japan: evidences from Japan Study Group of NAFLD. Integr Mol Med. (2015) 2. doi: 10.15761/IMM.1000130 
104. Boutari C, Mantzoros CS. Adiponectin and leptin in the diagnosis and therapy of NAFLD. Metabolism. (2020) 103:154028. doi: 10.1016/j.metabol.2019.154028

105. Sanal MG. Biomarkers in nonalcoholic fatty liver diseasethe emperor has no clothes? World J Gastroenterol. (2015) 21:3223-31. doi: 10.3748/wjg.v21.i11.3223

106. Tripathi D, Kant S, Pandey S, Ehtesham NZ. Resistin in metabolism, inflammation, and disease. FEBS J. (2020) 287:31419. doi: $10.1111 /$ febs. 15322

107. Grover B, Puri S, Tandon N. Nutrient-Adipokine Interaction in NAFLD: A Review. World J Nutr Heal. (2019) 7:30-4. doi: 10.12691/jnh-7-2-1

108. Musso G, Gambino R, Cassader M, Pagano G. Meta-analysis : Natural history of non-alcoholic fatty liver disease ( NAFLD ) and diagnostic accuracy of non-invasive tests for liver disease severity. Ann Med. (2011) 43:61749. doi: 10.3109/07853890.2010.518623

109. Choi HM, Doss HM, Kim KS. multifaceted physiological roles of adiponectin in inflammation and diseases. Int J Mol Sci. (2020) 21:1219. doi: $10.3390 /$ ijms 21041219

110. Yagmur E, Trautwein C, Leers MPG, Gressner AM, Tacke F. Elevated apoptosis-associated cytokeratin 18 fragments (CK18Asp386) in serum of patients with chronic liver diseases indicate hepatic and biliary inflammation. Clin Biochem. (2007) 40:651-5. doi: 10.1016/j.clinbiochem.2006.12.010

111. De Bruin EC, Van De Velde CJH, Van De Pas S, Nagtegaal ID, Van Krieken JHJM, Gosens MJEM, et al. Prognostic value of apoptosis in rectal cancer patients of the dutch total mesorectal excision trial: radiotherapy is redundant in intrinsically high-apoptotic tumors. Clin Cancer Res. (2006) 12:6432-6. doi: 10.1158/1078-0432.CCR-06-0231

112. Miyasato M, Murase-Mishiba Y, Bessho M, Miyawaki M, Imbe H, Tsutsumi C, et al. The cytokeratin-18 fragment level as a biomarker of nonalcoholic fatty liver disease in patients with type 2 diabetes mellitus. Clin Chim Acta. (2014) 433:184-9. doi: 10.1016/j.cca.2014.03.018

113. Chang $\mathrm{Y}$, Lin $\mathrm{H}$, Hwu D, Chang D, Lin K, Lee Y. Elevated serum cytokeratin-18 concentration in patients with type 2 diabetes mellitus and non-alcoholic fatty liver disease. Ann Clin Biochem. (2019) 56:1417. doi: $10.1177 / 0004563218796259$

114. Wang L, Yao M, Liu S, Yang D, Wen X, Ning J, et al. Serum golgi protein 73 as a potential biomarker for hepatic necroinflammation in population with nonalcoholic steatohepatitis. Dis Markers. (2020) 2020:6036904. doi: 10.1155/2020/6036904

115. Adams LA, Chan WK. Noninvasive tests in the assessment of NASH and NAFLD fibrosis: now and into the future. Semin Liver Dis. (2020) 40:3318. doi: 10.1055/s-0040-1713006

116. Dai G, Liu P, Li X, Zhou X, He S. Association between PNPLA3 rs738409 polymorphism and nonalcoholic fatty liver disease (NAFLD) susceptibility and severity: A meta-analysis. Medicine. (2019) 98. doi: 10.1097/MD.0000000000014324

117. Muyyarikkandy MS, Mcleod M, Maguire M, Mahar R, Kattapuram N, Zhang $\mathrm{C}$, et al. Branched chain amino acids and carbohydrate restriction exacerbate ketogenesis and hepatic mitochondrial oxidative dysfunction during NAFLD. FASEB J. (2020) 1-18. doi: 10.1096/fj.202001495R

118. Balakrishnan M. Loomba R. The role of noninvasive tests for differentiating NASH from NAFL and diagnosing advanced fibrosis among patients with NAFLD. J Clin Gastroenterol. (2021) 54:107-13. doi: 10.1097/MCG.0000000000001284

119. Traussnigg S, Kienbacher C, Gajdošík M, Valkovič L, Halilbasic E, Stift J, et al. Ultra-high-field magnetic resonance spectroscopy in non-alcoholic fatty liver disease: Novel mechanistic and diagnostic insights of energy metabolism in non-alcoholic steatohepatitis and advanced fibrosis. Liver Int. (2017) 37:1544-53. doi: 10.1111/liv.13451

120. Aydin MM, Akcali KC. Liver fibrosis. Turkish J Gastroenterol. (2018) 29:1421. doi: 10.5152/tjg.2018.17330

121. Roehlen N, Crouchet E, Baumen TE. Liver fibrosis : mechanistic concepts and therapeutic perspectives. Cells. (2020) 9:875. doi: 10.3390/cells9040875

122. Paul J. Recent advances in non-invasive diagnosis and medical management of non-alcoholic fatty liver disease in adult. Egypt Liver J. 10:1-18. doi: 10.1186/s43066-020-00043-x

123. Miele L, Alberelli MA, Martini M, Liguori A, Marrone G, Cocomazzi A, et al. Nonalcoholic fatty liver disease (NAFLD) severity is associated to a nonhemostatic contribution and proinflammatory phenotype of platelets. Transl Res. (2021) 231:24-38. doi: 10.1016/j.trsl.2020.11.003

124. Ghafoory S, Varshney R, Robison T, Kouzbari K, Woolington S, Murphy B, et al. Platelet TGF- $\beta 1$ deficiency decreases liver fibrosis in a mouse model of liver injury. Blood Adv. (2018) 2:470-80. doi: 10.1182/bloodadvances.2017010868

125. Schmitz SMT, Kroh A, Ulmer TF, Andruszkow J, Luedde T, Brozat JF, et al. Evaluation of NAFLD and fibrosis in obese patients-a comparison of histological and clinical scoring systems. BMC Gastroenterol. (2020) 20:19. doi: 10.1186/s12876-020-01400-1

126. Gawrieh S, Chalasani N. NAFLD fibrosis score: is it ready for wider use in clinical practice and for clinical trials? Gastroenterology. (2013) 145:7179. doi: 10.1053/j.gastro.2013.08.025

127. Marella HK, Reddy YK, Jiang Y, Ganguli S, Podila PSB, Snell PD, et al. Accuracy of noninvasive fibrosis scoring systems in african american and white patients with nonalcoholic fatty liver disease. Clin Transl Gastroenterol. (2020) 11:1-12. doi: 10.14309/ctg.0000000000000165

128. Peleg N, Issachar A, Sneh-Arbib O, Shlomai A. AST to platelet ratio index and fibrosis 4 calculator scores for non-invasive assessment of hepatic fibrosis in patients with non-alcoholic fatty liver disease. Dig Liver Dis. (2017) 49:1133-8. doi: 10.1016/j.dld.2017.05.002

129. Castera L, Friedrich-Rust M, Loomba R. Noninvasive assessment of liver disease in patients with nonalcoholic fatty liver disease. Gastroenterology. (2019) 156:1264-81. doi: 10.1053/j.gastro.2018.12.036

130. Huang C, Seah JJ, Tan CK, Kam JW, Tan J, Teo EK, et al. Modified AST to platelet ratio index improves APRI and better predicts advanced fibrosis and liver cirrhosis in patients with non-alcoholic fatty liver disease. Clin Res Hepatol Gastroenterol. (2020) 101528. doi: 10.1016/j.clinre.2020.08.006

131. Pérez-Gutiérrez OZ, Hernández-Rocha C, Candia-Balboa RA, Arrese MA, Benítez C, Brizuela-Alcántara DC, et al. Validation study of systems for noninvasive diagnosis of fibrosis in nonalcoholic fatty liver disease in Latin population. Ann Hepatol. (2013) 12:416-24. doi: 10.1016/S1665-2681(19)31004-X

132. Cheng $\mathrm{CH}$, Chu CY, Chen HL, Lin IT, Wu CH, Lee YK, et al. Subgroup analysis of the predictive ability of aspartate aminotransferase to platelet ratio index (APRI) and fibrosis-4 (FIB-4) for assessing hepatic fibrosis among patients with chronic hepatitis C. J Microbiol Immunol Infect. (2020) 53:542-9. doi: 10.1016/j.jmii.2019.09.002

133. Forns $\mathrm{X}$, Ampurdanès S, Llovet JM, Aponte J, Quintó L, MartínezBauer E, et al. Identification of chronic hepatitis C patients without hepatic fibrosis by a simple predictive model. Hepatology. (2002) 36:98692. doi: 10.1053/jhep.2002.36128

134. Güzelbulut F, Akkan Çetinkaya Z, Sezikli M, Yaşar B, Özkara S, Kurdaş Övünç AO. AST-platelet ratio index, Forns index and FIB-4 in the prediction of significant fibrosis and cirrhosis in patients with chronic hepatitis C. Turkish J Gastroenterol. (2011) 22:279-85. doi: 10.4318/tjg.2011.0213

135. Altamirano J, Qi Q, Choudhry S, Abdallah M, Singal AK, Humar A, et al. Non-invasive diagnosis: Non-alcoholic fatty liver disease and alcoholic liver disease. Transl Gastroenterol Hepatol. (2020) 5. doi: 10.21037/tgh.2019.11.14

136. Liebig S, Stoeckmann N, Geier A, Rau M, Schattenberg JM, Bahr $\mathrm{MJ}$, et al. Multicenter validation study of a diagnostic algorithm to detect NASH and fibrosis in NAFLD patients with low NAFLD fibrosis score or liver stiffness. Clin Transl Gastroenterol. (2019) 10:19. doi: $10.14309 / \mathrm{ctg} .0000000000000066$

137. Sun L, Wang Q, Liu M, Xu G, Yin H, Wang D, et al. Albumin binding function is a novel biomarker for early liver damage and disease progression in non-alcoholic fatty liver disease. Endocrine. (2020) 69:294302. doi: 10.1007/s12020-020-02319-Z

138. Lee J, Vali Y, Boursier J, Spijker R, Anstee QM, Bossuyt PM, et al. Prognostic accuracy of FIB-4, NAFLD fibrosis score and APRI for NAFLD-related events: a systematic review. Liver Int. (2021) 41:26170. doi: 10.1111/liv.14669

139. Naveau S, Lamouri K, Pourcher G, Njiké-Nakseu M, Ferretti S, Courie R, et al. The diagnostic accuracy of transient elastography for the diagnosis of liver fibrosis in bariatric surgery candidates with suspected NAFLD. Obes Surg. (2014) 24:1693-701. doi: 10.1007/s11695-014-1235-9

140. Zambrano-Huailla R, Guedes L, Stefano JT, de Souza AAA, Marciano S, Yvamoto E, et al. Diagnostic performance of three non-invasive fibrosis 
scores (Hepamet, FIB-4, NAFLD fibrosis score) in NAFLD patients from a mixed Latin American population. Ann Hepatol. (2020) 19:6226. doi: 10.1016/j.aohep.2020.08.066

141. Higuera-de-la-Tijera F, Córdova-Gallardo J, Buganza-Torio E, BarrancoFragoso B, Torre A, Parraguirre-Martínez S, et al. Hepamet fibrosis score in nonalcoholic fatty liver disease patients in mexico: lower than expected positive predictive value. Dig Dis Sci. (2021) 66:45017. doi: 10.1007/s10620-020-06821-2

142. Tilg H, Moschen AR, Roden M. NAFLD and diabetes mellitus. Nat Rev Gastroenterol Hepatol. (2017) 14:32-42. doi: 10.1038/nrgastro.2016.147

143. Guillaume M, Moal V, Delabaudiere C, Zuberbuhler F, Robic MA, Lannes A, et al. Direct comparison of the specialised blood fibrosis tests FibroMeterV2G and enhanced liver fibrosis score in patients with nonalcoholic fatty liver disease from tertiary care centres. Aliment Pharmacol Ther. (2019) 50:1214-22. doi: 10.1111/apt.15529

144. Kupčová $\mathrm{V}$, Fedelešová $\mathrm{M}$, Bulas J, Kozmonová $\mathrm{P}$, Turecký L. Overview of the pathogenesis, genetic, and non-invasive clinical, biochemical, and scoring methods in the assessment of NAFLD. Int J Environ Res Public Health. (2019) 16:3570. doi: 10.3390/ijerph16193570

145. Inadomi C, Takahashi H, Ogawa Y, Oeda S, Imajo K, Kubotsu Y, et al. Accuracy of the enhanced liver fibrosis test, and combination of the enhanced liver fibrosis and non-invasive tests for the diagnosis of advanced liver fibrosis in patients with non-alcoholic fatty liver disease. Hepatol Res. (2020) 50:682-92. doi: 10.1111/hepr.13495

146. Srivastava A, Jong S, Gola A, Gailer R, Morgan S, Sennett K, et al. Costcomparison analysis of FIB-4, ELF and fibroscan in community pathways for non-alcoholic fatty liver disease. BMC Gastroenterol. (2019) 19:115. doi: 10.1186/s12876-019-1039-4

147. Staufer K, Halilbasic E, Spindelboeck W, Eilenberg M, Prager G, Stadlbauer $\mathrm{V}$, et al. Evaluation and comparison of six noninvasive tests for prediction of significant or advanced fibrosis in nonalcoholic fatty liver disease. United Eur Gastroenterol J. (2019) 7:1113-23. doi: 10.1177/2050640619865133

148. Vali Y, Lee J, Boursier J, Spijker R, Löffler J, Verheij J, et al. Enhanced liver fibrosis test for the non-invasive diagnosis of fibrosis in patients with NAFLD: a systematic review and meta-analysis. J Hepatol. (2020) 73:25262. doi: $10.1016 /$ j.jhep.2020.03.036

149. Calès P, Boursier J, Oberti F, Hubert I, Gallois Y, Rousselet MC, et al. FibroMeters: a family of blood tests for liver fibrosis. Gastroenterol Clin Biol. (2008) 32:40-51. doi: 10.1016/S0399-8320(08)73992-7

150. Calès P, Boursier J, Chaigneau J, Lainé F, Sandrini J, Michalak S, et al. Diagnosis of different liver fibrosis characteristics by blood tests in non-alcoholic fatty liver disease. Liver Int. (2010) 30:134654. doi: 10.1111/j.1478-3231.2010.02314.x

151. Papagianni M, Sofogianni A, Tziomalos K. Non-invasive methods for the diagnosis of nonalcoholic fatty liver disease. World J Hepatol. (2015) 7:63848. doi: 10.4254/wjh.v7.i4.638

152. Rosato V, Masarone M, Aglitti A, Persico M. The diagnostic conundrum in non-alcoholic fatty liver disease. Explor Med. (2020) 1:259-86. doi: 10.37349/emed.2020.00018

153. De Silva S, Li W, Kemos P, Brindley JH, Mecci J, Samsuddin S, et al. Non-invasive markers of liver fibrosis in fatty liver disease are unreliable in people of south asian descent. Frontline Gastroenterol. (2018) 9:11521. doi: $10.1136 /$ flgastro-2017-100865

154. Morra R, Munteanu M, Imbert-Bismut F, Messous D, Ratziu V, Poynard T. FibroMAX ${ }^{\mathrm{TM}}$ : towards a new universal biomarker of liver disease? Expert Rev Mol Diagn. (2007) 7:481-90. doi: 10.1586/14737159.7.5.481

155. Lassailly G, Caiazzo R, Hollebecque A, Buob D, Leteurtre E, Arnalsteen L, et al. Validation of noninvasive biomarkers (FibroTest, SteatoTest, and NashTest) for prediction of liver injury in patients with morbid obesity. Eur J Gastroenterol Hepatol. (2011) 23:499-506. doi: 10.1097/MEG.0b013e3283464111

156. Munteanu M, Tiniakos D, Anstee Q, Charlotte F, Marchesini G, Bugianesi E, et al. Diagnostic performance of FibroTest, SteatoTest and ActiTest in patients with NAFLD using the SAF score as histological reference. Aliment Pharmacol Ther. (2016) 44:877-89. doi: 10.1111/apt.13770

157. Lardi LL, Lul RM, Port GZ, Coral GP, Peres A, Dorneles GP, et al. Fibromax and inflamatory markers cannot replace liver biopsy in the evaluation of non-alcoholic fatty liver disease. Minerva Gastroenterol Dietol. (2020)
158. Vali Y, Lee J, Boursier J, Spijker R, Verheij J, Brosnan M, et al. Fibrotest for evaluating fibrosis in non-alcoholic fatty liver disease patients: a systematic review and meta-analysis. J Clin Med. (2021) 10:2415. doi: $10.3390 / \mathrm{jcm} 10112415$

159. Yousaf MN, Chaudhary FS, Mehal WZ. The impact of scoring system in the evaluation of Nonalcoholic fatty liver disease (NAFLD) and nonalcoholic steatohepatitis (NASH). Gastroenterol Hepatol Open Access. (2019) 10:2626. doi: 10.15406/ghoa.2019.10.00392

160. Gunn NT, Shiffman ML. The use of liver biopsy in nonalcoholic fatty liver disease: when to biopsy and in whom. Clin Liver Dis. (2018) 22:10919. doi: 10.1016/j.cld.2017.08.006

161. Arab JP, Barrera F, Arrese M. The evolving role of liver biopsy in non-alcoholic fatty liver disease. Ann Hepatol. (2018) 17:899-902. doi: 10.5604/01.3001.0012.7188

162. Brunt EM. Nonalcoholic fatty liver disease and the ongoing role of liver biopsy evaluation. Hepatol Commun. (2017) 1:370-8. doi: 10.1002/hep4.1055

163. Huang J, Ou W, Wang M, Singh M, Liu Y, Liu S, et al. Criteria guide the subtyping of patients with fatty liver disease. Risk Manag Healthc Policy. (2021) 14:491-501. doi: 10.2147/RMHP.S285880

164. Oh H, Jun DW, Saeed WK, Nguyen MH. Non-alcoholic fatty liver diseases: update on the challenge of diagnosis and treatment. Clin Mol Hepatol. (2016) 22:327-35. doi: 10.3350/cmh.2016.0049

165. Canbay A, Kälsch J, Neumann U, Rau M, Hohenester S, Baba HA, et al. Non-invasive assessment of NAFLD as systemic disease-a machine learning perspective. PLoS ONE. (2019) 14:1-15. doi: 10.1371/journal.pone.0214436

166. De Silva S, Li W, Kemos P, Brindley JH, Mecci J, Samsuddin S, et al. Noninvasive markers of liver fibrosis in fatty liver disease are unreliable in people of South Asian descent. Frontline Gastroenterol. (2017) 9:flgastro2017-100865. doi: 10.1136/gutjnl-2017-314472.321

167. Önnerhag K, Hartman H, Nilsson PM, Lindgren S. Non-invasive fibrosis scoring systems can predict future metabolic complications and overall mortality in non-alcoholic fatty liver disease (NAFLD). Scand J Gastroenterol. (2019) 54:328-34. doi: 10.1080/00365521.2019.15 83366

168. Ratziu V, Giral P, Charlotte F, Bruckert E, Thibault V, Theodorou I, et al. Liver fibrosis in overweight patients. Gastroenterology. (2000) 118:111723. doi: 10.1016/S0016-5085(00)70364-7

169. Kaneva AM, Bojko ER. Age-adjusted cut-off values of lipid accumulation product (LAP) for predicting hypertension. Sci Rep. (2021) 11. doi: 10.1038/s41598-021-90648-y

170. Piazzolla VA, Mangia A. Noninvasive diagnosis of NAFLD and NASH. Cells. (2020) 9:1005. doi: 10.3390/cells9041005

171. Glen J, Floros L, Day C, Pryke R. Non-alcoholic fatty liver disease (NAFLD): summary of NICE guidance. Br Med J. (2016) 354. doi: 10.1136/bmj.i4428

172. National Institute for Health and Care Excellence. National Institute for Health and Care Excellence| NICE Guidance. (2016). p. 6.

173. Cariou B, Byrne CD, Loomba R, Sanyal AJ. Nonalcoholic fatty liver disease as a metabolic disease in humans: a literature review. Diabetes, Obes Metab. (2021) 23:1069-83. doi: 10.1111/dom.14322

Conflict of Interest: The authors declare that the research was conducted in the absence of any commercial or financial relationships that could be construed as a potential conflict of interest.

Publisher's Note: All claims expressed in this article are solely those of the authors and do not necessarily represent those of their affiliated organizations, or those of the publisher, the editors and the reviewers. Any product that may be evaluated in this article, or claim that may be made by its manufacturer, is not guaranteed or endorsed by the publisher.

Copyright $\odot 2022$ Segura-Azuara, Varela-Chinchilla and Trinidad-Calderón. This is an open-access article distributed under the terms of the Creative Commons Attribution License (CC BY). The use, distribution or reproduction in other forums is permitted, provided the original author(s) and the copyright owner(s) are credited and that the original publication in this journal is cited, in accordance with accepted academic practice. No use, distribution or reproduction is permitted which does not comply with these terms. 